\title{
Quimioluminescência: Uma proposta experimental simples e de baixo custo para o assunto de Estrutura Atômica
}

\section{Chemiluminescence: a simple low cost experimental proposal for the Atomic Structure subject}

\author{
Antony Ernesto dos Santos Silva ${ }^{1^{*}}$ \\ ${ }^{1}$ Licenciado em Química, Especialista em Ensino de Ciências Naturais, Mestrando em Ciências Farmacêuticas pela Universidade Federal do \\ Alagoas. Brasil. E-mail: antonyessilva@gmail.com * Autor para correspondência
}

\author{
Palavras-chave \\ Quimioluminescência \\ Experimentação \\ Teoria-prática \\ Aprendizagem
}

Neste trabalho é apresentada uma proposta de experimentação, simples e de baixo custo, que pode ser aplicada para a consolidação da aprendizagem referente ao assunto de Estrutura Atômica. Esta proposta foi elaborada tendo como base um questionário que foi aplicado nas três séries do Ensino Médio de uma escola pública da rede estadual de ensino do estado de Alagoas, para saber o que os alunos achavam da disciplina de Química, da metodologia que o professor usava para passar os conteúdos da disciplina, bem como o que poderia ser feito pelo professor para melhorar as aulas da mesma e se eles enxergavam a Química no cotidiano. Através das respostas da maioria dos alunos ao questionário em tese, ficou claro que a disciplina de Química, desta escola, precisa ser mais atrativa, contextualizada, e abordada de forma diferente da que foi observa. Tal problema pode ser resolvido ao aplicar a proposta experimental apresentada neste trabalho, após as aulas sobre Estrutura Atômica, uma vez que ela é simples e de baixo custo, não precisando de laboratório para a sua realização. Assim haverá uma relação entre a teoria e a prática o que pode melhorar o desempenho dos alunos significativamente.

\section{Keywords \\ Chemiluminescence \\ Experimentation \\ Theory-practice \\ Learning}

\begin{abstract}
This paper presents a simple and inexpensive experimentation proposal that can be applied to the consolidation of learning related to the subject of Atomic Structure. This proposal was elaborated based on a questionnaire that was applied, in the three grades of a high school of a public school of the state school of the state of Alagoas, to know what the students thought of the discipline of chemistry, the methodology that the teacher I used to pass the contents of the course, as well as what could be done by the teacher to improve the classes and if they saw chemistry in everyday life. Through the answers of most students to the thesis questionnaire, it was clear that the chemistry discipline of this school needs to be more attractive, contextualized, and approached differently than it was observed. This problem can be solved by applying the experimental proposal presented in this paper after the Atomic Structure classes, since it is simple and inexpensive and does not require a laboratory for its realization. Thus there will be a relationship between theory and practice which can significantly improve student performance.
\end{abstract}

\section{INTRODUÇÃO}

Vários pesquisadores na área da Educação em Ciências da Natureza têm estudado, durante anos, a relação entre a teoria e prática e a sua eficácia na construção de conhecimento quando aplicada. Muitos trabalhos foram elaborados e até publicados, mas quando observamos a realidade de algumas escolas, principalmente as menos favorecidas, que não possuem laboratório, percebemos que a relação teoriaprática se torna mais distante, deixando de lado uma ferramenta muito eficaz na consolidação do conhecimento, que é a experimentação.

Dito isto, neste trabalho é apresentada uma proposta de experimentação, simples e debaixo custo, que pode ser aplicada para a consolidação da aprendizagem referente ao assunto de Estrutura Atômica, que vem como uma alternativa para resolver os problemas encontrados nesta escola, sobre a disciplina de Química e o assunto em tese.

Esta proposta foi elaborada quando um questionário foi aplicado, nas três séries do Ensino Médio de uma escola pública da rede estadual de ensino do Estado de Alagoas, para saber o que os alunos achavam da disciplina de Química, da metodologia que o professor usava para passar os conteúdos da disciplina, bem como o que poderia ser feito pelo professor para melhorar as aulas da mesma e se eles enxergavam a Química no cotidiano.

Percebe-se, através das respostas da maioria dos alunos ao questionário aplicado, que a disciplina de Química é de difícil compreensão; que o professor é o principal responsável em tornar a aula da disciplina mais legal e atraente; que aula 
se tornará mais interessante se o professor fizer experimentação em suas aulas para que haja melhor compreensão dos conteúdos passados; e que eles enxergavam a Química no cotidiano como parte de suas vidas.

\section{A ilimitação da Química enquanto ciência}

A ciência nos permite enxergar o mundo natural de outra forma, de uma forma que vai além do abstrato ou da via indireta de conhecimento, onde podemos ter explicações de fatos e acontecimentos que outrora não nos era permitido saber. Um exemplo muito comum é como o homem buscava entender a origem do mundo, onde em todas as culturas foram criadas diferentes explicações para o surgimento do universo.

Os gregos, por exemplo, criaram a mitologia que conta a história da criação do mundo, do homem e de acontecimentos remotos (BERTOLDI; VASCONSELLOS, 2000). Mas podemos comprovar e ter uma ideia de como o universo surgiu, através de provas científicas. Outros exemplos podem ser dados, como o avanço da ciência na cura de doenças incuráveis, etc. Desta forma a ciência nos permite sair de suposições para comprovações, ou seja, ter um olhar crítico sobre os fenômenos e acontecimentos que ocorrem no mundo e no universo, através do conhecimento científico.

É desta forma que a Química precisa ser vista e ensinada, de uma forma que nos possibilite romper as barreiras da ignorância científica, já que o conhecimento da mesma é importante até para nossa sobrevivência, já que seu estudo deve-se principalmente ao fato de desenvolver no homem uma visão crítica do mundo que o cerca, podendo analisar, compreender e utilizar este conhecimento no cotidiano, tendo condições de perceber e interferir em situações que contribuem para a deterioração de sua qualidade de vida (CARDOSO; COLINVAUX, 2000).

Tal visão sobre a importância de se estudar Química, só pode ser ensinada nas escolas, onde o senso crítico do aluno será despertado. Ora, como ter um senso crítico se não tiver o conhecimento sobre o assunto? Por isso a importância do conhecimento Químico neste processo de construção de conhecimento. Mas infelizmente, a Química é vista apenas como uma disciplina comum, não só pelos alunos, mas também pelos docentes, que não trazem o da mesma de uma forma correta, ou seja, contextualizada.

Para solucionar este problema, a experimentação se torna uma proposta promissora para a consolidação de conhecimentos anteriormente passados pelos professores nas aulas, uma vez que ela integra a teoria à pratica rumo a uma aprendizagem significativa, além de fazer com que os alunos pensem de forma crítica sobre o mundo e os acontecimentos que os cercam.

\section{Quimioluminescência: uma experimentação para o assunto de Estrutura Atômica}

A Base Nacional Comum Curricular (BNCC) do Ensino Médio, afirma que práticas de investigação, como atividades experimentais, por exemplo, merecem destaque especial na área desta modalidade da Educação Básica:

Os processos e práticas de investigação merecem também destaque especial nessa área. Portanto, a dimensão investigativa das Ciências da Natureza - por meio de um olhar articulado da Biologia, da Física e da Química - deve ser enfatizada no Ensino Médio, aproximando os estudantes dos procedimentos e instrumentos de investigação, tais como: identificar problemas, formular questões, identificar informações ou variáveis relevantes, propor e testar hipóteses, elaborar argumentos e explicações, escolher e utilizar instrumentos de medida, planejar e realizar atividades experimentais e pesquisas de campo, relatar, avaliar e comunicar conclusões e desenvolver ações de intervenção, a partir da análise de dados e informações sobre as temáticas da área (BRASIL, 2017, p.550).

Desta forma, fica claro que a experimentação é uma ferramenta de muita utilidade para consolidação de conhecimento. Ela pode ser usada pelo docente no Ensino de Química, pois servirá de ponte para alcançar uma aprendizagem significativa, numa relação teoria e prática, onde com esta relação será feita a junção do que o aluno já sabe com o que ele irá aprender. Muitas vezes o aluno não sabe de nada do que está sendo passado, mas com a experimentação, tais conhecimentos podem ser aprendidos de uma forma mais eficaz que na teoria.

Isso só é possível se a experimentação for feita adequadamente, ou seja, de forma investigativa e problematizada, já que ela é empregada anteriormente à discussão conceitual, e após as aulas teóricas, e visa obter informações que subsidiem a reflexão, as ponderações e as explicações, de forma que o aluno compreenda não só os conceitos, mas as diferentes formas de pensar e falar sobre o mundo por meio da ciência (JUNIOR; FERREIRA; HARTWIG, 2008).

Visto isto, a proposta de experimentação apresentada neste trabalho é uma reação quimioluminescente que pode ser aplicada para a consolidação da aprendizagem, 
relacionando teoria e prática, para o assunto de Estrutura Atômica, graças à afinidade existente entre a proposta e o assunto.

Ela é bem mais empregada à estrutura atômica de Bohr, uma vez que ele descreveu seu novo modelo de átomo (Figura 1) baseado em quatro postulados ao afirmar que um gás emite luz quando uma corrente elétrica passa por ele, devido aos elétrons em seus átomos primeiro absorverem energia da eletricidade e depois liberá-la na forma de luz (RUSSEL, 1994, apud SILVA 2013, p. 52).

Em seu primeiro postulado, Bohr sugeriu que um elétron, em um átomo, se move em uma órbita circular ao redor do núcleo com influência da atração existente entre eles. Enquanto o elétron permanecer na mesma órbita não emite energia. Essas órbitas correspondem aos estados estacionários.

Figura 1. Modelo atômico de Bohr.

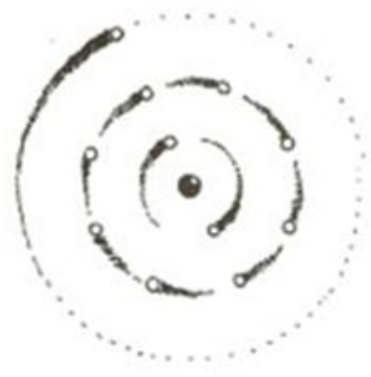

O segundo postulado afirma que em vez de infinitas órbitas, possíveis na mecânica clássica, um elétron se move apenas em uma órbita na qual seu movimento angular (L) é múltiplo inteiro de $\mathrm{h}$ (constante de Planck dividida por $2 \pi$ ). 0 problema da estabilidade de um elétron se movendo em uma órbita circular, devido à emissão de radiação eletromagnética pelo elétron, apresentado pelo modelo atômico de Rutherford (modelo atômico sugerido anterior ao de Bohr) foi resolvido pelo terceiro postulado, onde Bohr enunciou que apesar de estar constantemente acelerado, um elétron que se move em uma dessas órbitas possíveis, permanece com sua energia total (E) constante, não emitindo radiação eletromagnética (SILVA, 2013).

Bohr descreve seu último postulado afirmando que um átomo naturalmente se encontra em seu estado fundamental, ou seja, no estado no qual todos seus elétrons estão nos níveis de energia mais baixos que lhes são disponíveis. Ao absorver energia, de uma chama ou descarga elétrica, alguns elétrons do átomo são elevados a um nível de energia maior, ou seja, em um estado excitado (RUSSEL, 1994).

De forma simples, podemos dizer que para os elétrons saltarem para um nível mais alto, ocorre a absorção de energia em quantidade suficiente para promover tal salto. Ao retornarem ao seu estado fundamental, liberam a energia que foi absorvida, durante o processo, na forma de fótons. Tal fato pode ser observado na Figura 2 e representado pela equação matemática $\left(E_{2}\right)_{\text {elétron }}-\left(E_{1}\right)_{\text {elétron }}=$ h.v (SILVA, 2018).

Figura 2. Retorno do elétron de um átomo ao seu estado fundamental, liberando energia em forma de fótons.
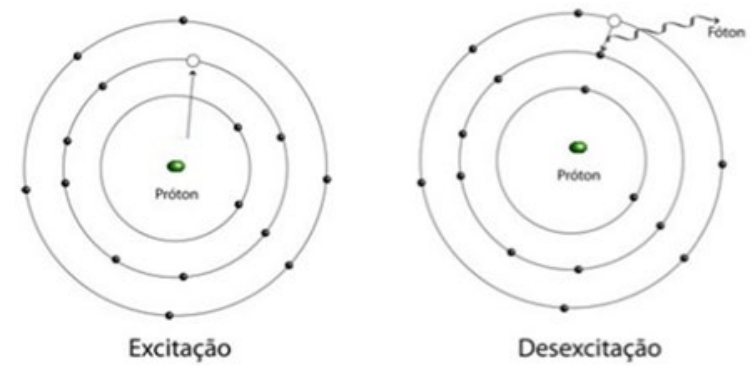

Fonte: adaptado de FONSECA, 2014.

Além do modelo atômico de Bohr, esta proposta pode ser aplicada para o modelo dos Orbitais Atômicos, sendo que para este, seria necessário conhecimentos mais detalhados e aprofundados, o que é mais bem visto no Ensino Superior, particularmente para a disciplina de Química Inorgânica.

Na quimioluminescência não é diferente, uma vez que é um fenômeno que ocorre devido à quebra de ligações ricas em energia, tais como, peróxidos, hidroperóxidos ou 1,2dioxetanos, já existentes nas moléculas ou formadas a partir de rearranjos moleculares (intermediários), onde o produto da reação é excitado e, ao retornar ao estado fundamental, emite fótons, caracterizando a quimioluminescência direta, ou, poderá transferir sua energia para outra molécula, sendo então, quimioluminescência indireta (SANTOS; SANTOS; COSTA, 1993).

A proposta de experimentação apresentada neste trabalho é uma reação quimioluminescente que ocorre em pulseiras luminosas (Figura 3). Quando misturados, o peróxido de hidrogênio (1) oxida o éster de fenil oxalato (2) para formar fenol (3) e um dímero de alta energia de dióxido de carbono, também conhecido como1,2-dioxetanodiona (4). Esse dímero por ser altamente instável, decompõe-se em duas moléculas de dióxido de carbono (5), gerando grande quantidade de energia que é transferida ao corante (6). Devido à energia absorvida, os elétrons do corante são excitados a um nível mais externo (7), e ao retornarem ao seu estado fundamental liberam essa energia na forma de luz (8) (Figura 4) (KUNTZLEMAN; COMFORT; BALDWIN, 2009).

Um fator positivo desta proposta é que a mesma pode ser realizada na sala de aula, sem precisar de um laboratório, uma vez que os reagentes e materiais utilizados para a sua realização são de fácil aquisição e baixo custo, o que a torna 
muito mais viável.

Figura 3. Etapas da reação que ocorre em pulseiras luminosas.
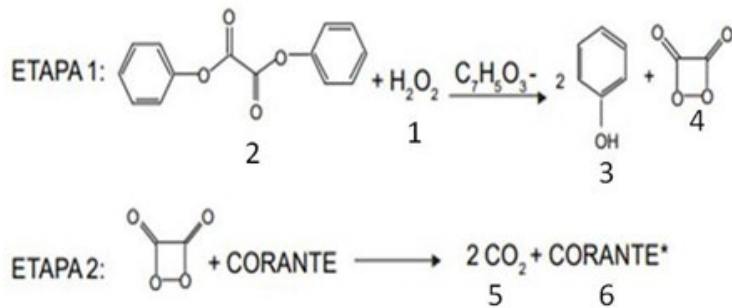

ETAPA3: CORANTE* $\longrightarrow$ CORANTE + h.v

7

8

Fonte: adaptado de KUNTZLEMAN; COMFORT; BALDWIN, 2009.

Figura 4. Reação quimioluminescente que ocorre nas pulseiras luminosas.

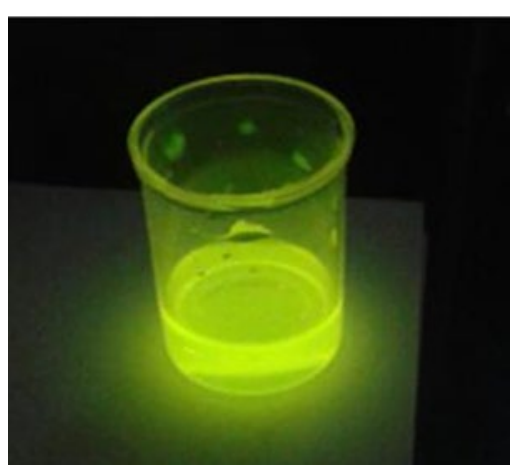

Fonte: Autor (2019).

\section{MATERIAL E MÉTODOS}

Para que a proposta experimental deste trabalho fosse elaborada, um questionário (Questionário aplicado p. 132) contendo 7 questões, 6 abertas e 1 fechada, foi aplicado nas três séries do Ensino Médio de uma escola pública da rede estadual de ensino do estado de Alagoas, para saber o que os alunos achavam da disciplina de Química, da metodologia que o professor usava para passar os conteúdos da disciplina, bem como o que poderia ser feito pelo professor para melhorar as aulas da mesma. Um total de 71 alunos respondeu o questionário, cujas respostas estão nos Resultados e Discussões deste trabalho.

Através das falas dos discentes e de suas respectivas respostas ao questionário, esta proposta experimental foi elaborada para atender às necessidades desta escola e de várias outras que não possuem laboratório de práticas experimentais em suas dependências.

Vale salientar que os reagentes utilizados (soluções de éter de fenil oxalato com corante luminescente e de peróxido de hidrogênio) para fazer a reação apresentada nas Figuras 3 e 4, para este trabalho, foram isolados de pulseiras luminosas que foram compradas comercialmente em um mercado popular da cidade, além de pequenos recipientes, totalizando um valor baixo ( $<\$ 30,00$ por 100 unidades de pulseiras). A reação química em tese ocorre quando as duas soluções reagentes são misturadas em um mesmo recipiente, durando a emissão de luz cerca de 6 a 8 horas.

\section{RESULTADOS E DISCUSSÃO}

Dos 71 alunos do Ensino Médio que responderam ao questionário, 34 eram da primeira série, 19 da segunda e 18 da terceira. Assim dividimos as perguntas e as respostas, seguidas de seus respectivos resultados e discussões, como mostrado abaixo, onde em negrito se encontram as perguntas do questionário utilizado.

“O que você acha da disciplina de química, é chata, é difícil, é ruim...? Justifique sua resposta."

Na Figura 5, é apresentado os dados, em percentuais do número de alunos, referente às respostas dos mesmos a esta pergunta.

Figura 5. Percentuais dos números de alunos e suas respectivas respostas referentes à primeira pergunta.

\section{$\square$ DIFÍCIL $\square$ BOA $\square$ CHATA $\square$ NECESSÁRIA}

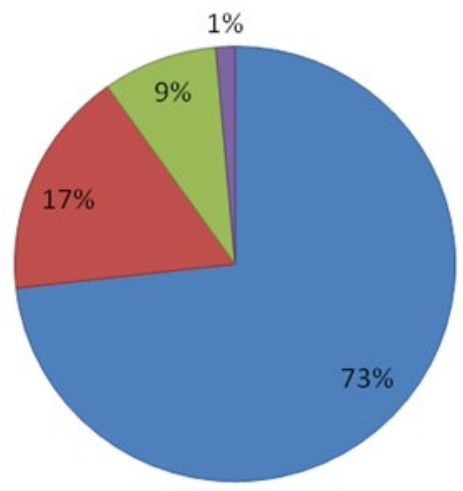

Nesta pergunta, dos 71 alunos que responderam o questionário, $73 \%$ disseram que a disciplina era difícil e na justificativa deles, disseram que ela tem muitos cálculos, o que a torna mais difícil de aprender, pois foi notado, com as observações feitas em sala de aula, que eles tinham dificuldade em matemática. Outros alunos afirmaram que os assuntos de química são difíceis e por serem muitos fica difícil de assimilar. Outros afirmaram que tem dificuldade em aprender esta disciplina, por isso ela se torna difícil. 
Já $17 \%$ acharam ela boa, pois a maioria justifica, com respostas quase que iguais, que aprendem coisas interessantes. Outros $9 \%$ afirmaram ser chata, onde maioria afirmou que é chata porque eles não gostam desta disciplina. E por fim, 1\% a acharam interessante por ser necessário estudá-la.

Percebe-se assim, que há um misto de dificuldades que os alunos enfrentam ao se tratar da disciplina de Química, que são evidenciadas por esta pergunta, são eles: dificuldades em cálculos, de assimilação, além do inconveniente de se depararem com o acúmulo de conteúdos que não aprenderam o que gera conflitos na aprendizagem. A dificuldade de assimilação remete à falta de contextualização, por parte do professor, ao passar os conteúdos, o que torna a disciplina chata e difícil, opinião da maioria dos alunos (73\%).

“Você acha necessário estudar Química? Por quê?”

É apresentado no gráfico abaixo (Figura 6) o número de alunos e as suas respostas, em percentuais, a fim de saber se eles achavam necessário estudar a disciplina de Química e o porquê.

Figura 6. Número de alunos e as suas respostas, em percentuais, referentes à segunda pergunta.

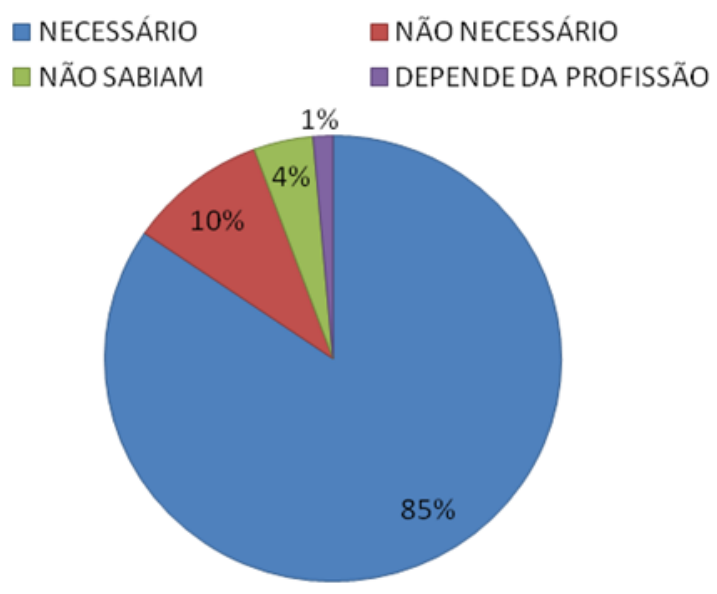

Percebe-se que $85 \%$ dos discentes afirmaram que era necessário estudar Química, onde alguns justificaram que iriam precisar dos conhecimentos aprendidos na sala de aula no futuro. Outros, porque pretendem seguir profissões que usará os conhecimentos químicos. Já alguns, justificaram ser necessário estudá-la por ela abrir os conhecimentos. Outros, afirmaram que ela é necessária para conhecer as coisas ao nosso redor onde a mesma está presente, e outros porque precisam estudá-la para passar de ano, pois a disciplina faz parte do roteiro de estudos.

Já outro grupo que compõe $10 \%$ do total de alunos, que responderam ao questionário, disseram que não era necessário estudá-la, porque é muito ruim, chata e desnecessária. Outros $4 \%$ afirmaram que não sabiam e $1 \%$ disseram que dependia da profissão que iriam seguir.

Esta questão, e as respectivas respostas dos alunos a ela, mostra que eles enxergam a Química como uma disciplina que, de alguma forma, os ajudarão no futuro. Entretanto, eles não conseguem perceber quais assuntos usarão e como usarão, tendo a maioria afirmado que é necessário estudá-la. A falta de contextualização e uso de uma metodologia eficaz na aprendizagem reflete os $10 \%$ que afirmam não ser necessário estudá-la, repetindo-se a fala de que a disciplina é chata e ruim, mostrando que o ensino da disciplina de Química, nesta escola, precisa ser melhorado.

"Em sua opinião, o que o professor deve fazer para melhorar o ensino da disciplina de Química?"

Esta questão foi a única fechada, onde procuramos saber as opiniões dos alunos sobre o que o professor deveria fazer para melhorar as aulas e o Ensino de Química nesta escola. As opções foram: "Fazer experimentos em sala de aula", "trazer filmes sobre os assuntos", "usar slides em um data show para explicar os assuntos" e "outros", sendo esse "outros" uma alternativa aberta para que os alunos expressassem suas respostas caso tivessem outras sugestões sobre a pergunta. Os dados referentes ao percentual de alunos, e suas respectivas respostas, para esta pergunta, estão na Figura 7.

Figura 7. Percentual de alunos e suas opiniões referentes a pergunta em tese.

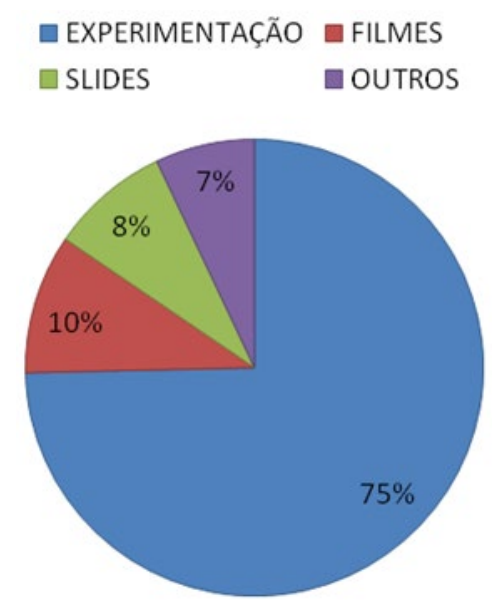

Nesta questão $75 \%$ dos alunos afirmaram que a prática de experimentos em sala de aula melhoraria o ensino da disciplina. Já $10 \%$ afirmaram que trazer filmes seria a sugestão para tornar o ensino da disciplina melhor. Outros $8 \%$ afirmaram que usar slides nas aulas era a sugestão correta e 7\% assinalaram a opção "outros", mas não colocaram uma sugestão.

Como mostra os dados, a maioria escolheu a opção "Fazer 
experimentos em sala de aula", comprovando que o Ensino de Química, nesta escola, precisa proporcionar uma proximidade entre os conteúdos ensinados e os alunos. Este inconveniente pode ser superado ao fazer experimentação com uma discussão que a antecede, tendo como base a contextualização, onde os alunos enxerguem a Química no seu dia a dia.

Esta questão foi primordial para a elaboração da proposta experimental apresentada neste trabalho, uma vez que ao explorar as reações quimioluminescentes que ocorre nas pulseiras luminosas é possível trazer situações do cotidiano em que a mesma está envolvida. Por exemplo, bastões de luz são usados pelos agentes da S.W.A.T., nos Estados Unidos, para marcar o caminho com baixa luminosidade, por onde eles já passaram ao fazer as operações, para evitar repetir o percurso ou andar em círculos. Outra contextualização, que se pode fazer também, é a explicação de como funciona uma lâmpada fluorescente, de luz branca (lâmpadas que funcionam em residências), embora uma reação quimioluminscênte tenha conceitos diferentes, mas o mecanismo de funcionamento é basicamente o mesmo, ou seja, emissão de luz derivada do retorno do elétron excitado a um nível de menor energia do átomo participante deste fenômeno.

Desta forma, fica evidente que com a experimentação aplicada nestas perspectivas de contextualização e metodologia, como citado no referencial teórico deste trabalho, o Ensino de Química pode se tornar mais fácil no sentido de aprendizagem eficaz, além de tornar a disciplina mais interessante e atrativa.

"Você acha que uma boa aula de Química depende dos conteúdos estudados ou da forma com que eles são passados pelo professor? Justifique sua resposta."

Nesta questão procurou-se saber se os alunos enxergavam o professor como principal mediador do ensinoaprendizagem deles, além de analisar a prática docente nesta escola referente à disciplina de Química. Na Figura 8 observamos as opiniões dos alunos para esta questão.

Um total de $56 \%$ dos alunos afirmou ser o professor o responsável para que a aula de Química seja boa e interessante, pois a maioria expressou que se o professor não explica bem o conteúdo, de forma que eles assimilem o assunto passado, as aulas se tornam chatas. Outros $7 \%$ afirmaram que para as aulas de Química serem boas, depende dos conteúdos estudados, não afirmando o porquê da resposta. Já $13 \%$ disseram que depende dos dois, pois se o professor não explicar bem os conteúdos e eles forem difíceis de entender, ou até muito complicados, a aula se tornará ruim. E por fim, $24 \%$ foram classificados como outros, por afirmarem que não sabiam ou por responderem de forma incoerente ao que foi perguntado.

Percebe-se, na opinião da maioria dos alunos, expressada nas respostas da questão acima, que o professor, por algum motivo, não explica bem os conteúdos que são passados, tornando a disciplina de difícil compreensão e consequentemente chata. Isto pode está acontecendo em função de várias variáveis, tais como: desinteresse da turma em aprender, já que julgam a disciplina difícil (conforme as respostas deles na primeira questão); sobrecarga de aulas do professor da disciplina, tornando a sua prática docente tradicional e monótona, prejudicando a aprendizagem dos alunos, uma vez que eles aprendem de maneiras diferentes um dos outros, e por isso, faz-se necessário ensinar o mesmo assunto de formas diferentes; ou o professor já ter muitos anos de magistério e esteja cansado de inovar em suas aulas.

Duas parcelas do total de alunos (13 e 7\%) conseguem enxergar a harmonia que deve existir entre a prática docente e os conteúdos passados. Quando esta existe, a aula se torna mais interessante, podendo-se alcançar uma aprendizagem mais eficaz.

Figura 8. Percentual de alunos e suas opiniões que refletem a prática docente nesta escola, para a disciplina de Química.

\section{PROFESSOR \\ CONTEÚDOS ESTUDADOS}

\section{$\square$ PROFESSORE CONTEÚDOS — OUTROS}

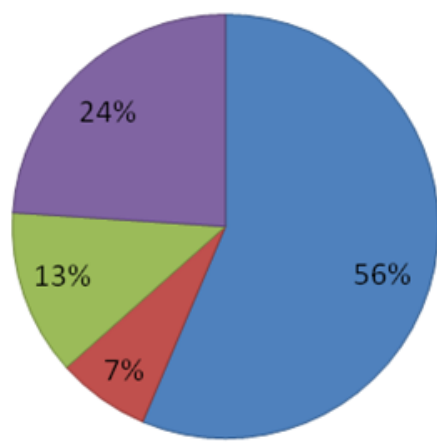

"Durante a sua vida você acha que vai precisar dos conhecimentos químicos aprendidos na escola?"

"Você acredita que a Química Ihe ajuda a refletir sobre o mundo em geral? Por quê?"

Estas duas questões foram formuladas com o objetivo de saber se os alunos conseguiam enxergar que eram capazes de serem atuantes na sociedade, como cidadãos críticos, usando os conhecimentos da disciplina aprendidos na escola.

A maioria (86\%) afirmaram que sim, pois precisariam na profissão em que pretendiam seguir. Já $13 \%$ afirmaram que 
não, pois disseram que não pretendiam fazer faculdade. E $1 \%$ afirmaram que não sabiam (Figura 9).

Figura 9. Perspectivas dos alunos, expressadas em suas opiniões, sobre se vão precisar dos conhecimentos químicos aprendidos na escola.

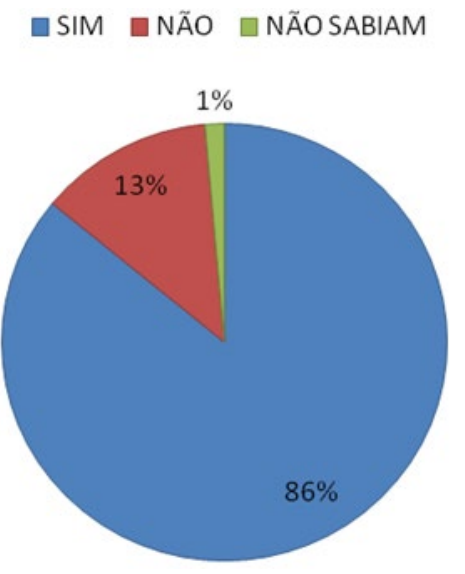

Já na Figura 10, referente a pergunta se a Química ajuda a refletir sobre o mundo, $63 \%$ afirmaram que sim, pois disseram que tudo depende da Química, porque em tudo ela está presente, principalmente na natureza, inclusive no nosso dia a dia. Já $21 \%$ afirmaram que ela não ajuda a refletir sobre o mundo em geral, não justificando suas respostas. Outros $13 \%$ disseram que não sabiam. E $3 \%$ forma classificados como "outros" por responderem de forma incoerente.

Figura 10. Opiniões dos alunos, expressadas em suas respostas, se a Química ajuda a refletir sobre o mundo em geral.

\section{SIM nÃ̃O NÃOSABEM mOUTROS}

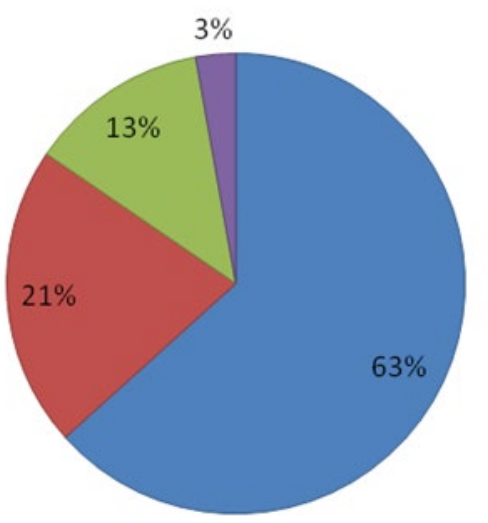

Com estas duas questões notamos que os alunos sabem que vão precisar dos conhecimentos sobre Química aprendidos na escola, porém não sabem dizer aonde eles os usarão. Alguns até afirmam que em tudo há Química, principalmente na natureza e no cotidiano, porém não conseguem expressar o que eles podem fazer, com simples atos, para preservar a natureza, como separar os diversos tipos de lixos e descartá-los da forma correta, por exemplo. Percebe-se também que uma parcela destes alunos enxerga a Química apenas como uma disciplina que se precisa estudar para obter a média e passar nas provas, o que é lamentável. Esta perspectiva errônea pode ser mudada com a prática docente.

Desta forma enfatizamos que o Ensino de Química pode formar também cidadãos críticos, capazes de intervir na sociedade para a sua melhoria de vida, e isso deve ser ensinado nas aulas da disciplina nas escolas.

\section{CONSIDERAÇÕES FINAIS}

A experimentação ajuda os alunos a consolidar conhecimentos aprendidos anteriormente nas aulas de Química, uma vez que ao aplicá-la, após as aulas teóricas, ocorre uma relação intrínseca entre a teoria e a prática, garantindo ao alunado uma aprendizagem significativa e eficaz.

Percebe-se, através das respostas da maioria dos alunos ao questionário aplicado, que a disciplina de Química é de difícil compreensão; que o professor é o principal responsável em tornar a aula da disciplina mais legal e atraente; que aula se tornará mais interessante se o professor fizer experimentação em suas aulas para que haja melhor compreensão dos conteúdos passados; e que eles enxergavam a Química no cotidiano como parte de suas vidas. Tais respostas são o reflexo do Ensino de Química, da prática docente do professor e da visão dos alunos sobre as aulas da disciplina, desta escola, bem como de suas perspectivas de vida e formação.

A proposta experimental, apresentada neste trabalho, se torna promissora para a consolidação da aprendizagem de conhecimentos referente ao assunto de Estrutura Atômica da disciplina de Química da escola em tese, podendo ser aplicada em outras escolas que não possuem laboratório, uma vez que os reagentes são de baixo custo e de fácil obtenção, tornando esta experimentação com caráter simples de realização.

\section{REFERÊNCIAS}

ABDALLA, M. C. B. Bohr: o arquiteto do átomo, 2 ed., São Paulo: Odysseus, 2006.

BERTOLDI, O. G.; VASCONSELLOS, J. R. Ciência e Sociedade: a aventura do corpo, a aventura da vida, a aventura da tecnologia. Scipione, São Paulo, 2000.

BRASIL. Base Nacional Comum Curricular (BNCC). Educação é a Base. Brasília, MEC/CONSED/UNDIME, 2017. Disponível 
em:

<http://basenacionalcomum.mec.gov.br/images/BNCC_E I_EF_110518_versaofinal_site.pdf>. Acesso em: 30 jun. 2019.

CARDOSO, S. P.; COLINVAUX, D. Explorando a motivação para estudar química. Química Nova, São Paulo, v.23, n.3, p.401-404, 2000. Disponível em: <http://www.scielo.br/pdf/qn/v23n3/2827.pdf>. Acesso em: 10 ago. 2019.

FONSECA, M. R. Química 1. 1ạ ed. - ed Ática, São Paulo, 2014. JÚNIOR, F. W. E.; FERREIRA, L. H.; HARTWIG, D. R. Experimentação Problematizadora: Fundamentos Teóricos e Práticos para a Aplicação em Salas de Aula de Ciência. Química Nova na Escola, São Paulo, n.30, p.34-41, $2008 . \quad$ Disponível em: $<$ http://qnesc.sbq.org.br/online/qnesc30/07-PEQ4708.pdf>. Acesso em: 14 ago. 2019.

KUNTZLEMAN, T. S.; COMFORT, A. E.; BALDWIN, B. W. Glowmatography. Journal of Chemical Education. Washington, v.86, n.1, p.64-67, 25 jun. 2019.

RUSSEL, J. B. Química Geral. Tradução: Márcia Guekezian et al., São Paulo: Makron Books, 1994.

SANTOS, R. M. S.; SANTOS, M. F.; COSTA, M. F. D. Quimioluminescência e Bioluminescência. Química Nova,São Paulo, v.16, n.3, p.200-209, 1993. Disponível em: <http://quimicanova.sbq.org.br/imagebank/pdf/Vol16No 3_200_v16_n3_\%286\%29.pdf>. Acesso em: 2 set. 2019.

SILVA, C. A.Modelos atômicos como objeto do saber no ensino de química: uma proposta metodológica baseada em elementos da engenharia didática. Dissertação de mestrado. Feira de Santana, BA, Brasil. 2018. Disponível em:

<http://tede2.uefs.br:8080/bitstream/tede/651/2/CESAR \%20ALVES_Disserta\%C3\%A7\%C3\%A3o_Final\%20revisado \%20vera.pdf>. Acesso em: 3 set. 2019.

SILVA, G. S. A abordagem do modelo atômico de Bohr através de atividades experimentais e de modelagem. Dissertação de mestrado. Santa Maria, RS, Brasil. 2013. Disponível em: <http://w3.ufsm.br/ppgecqv/Docs/Dissertacoes/GIOVAN NA.pdf>. Acesso em: 3 set. 2019 ..

\section{Questionário Aplicado:}

1. O que você acha da disciplina de química, é chata, é difícil, é ruim....? Justifique sua resposta.

2. Você acha necessário estudar química? Por quê?

3. Em sua opinião, o que o professor deve fazer para melhorar o ensino da disciplina de química?

( ) Fazer experimentos químicos em sala de aula

( ) Trazer filmes sobre o assunto

( ) Usar slides em um data show para explicação dos assuntos

( ) Outros. O que?

4. Você acha que uma boa aula depende dos conteúdos estudados ou da forma com que eles são passados pelo professor? Justifique sua resposta.

5. Durante a sua vida você acha que vai precisar dos conhecimentos químicos aprendidos na escola?

6. Você acredita que a química lhe ajuda a refletir sobre o mundo em geral? Por quê? 